\title{
Monetary Actions, Credit Flows and Inflation
}

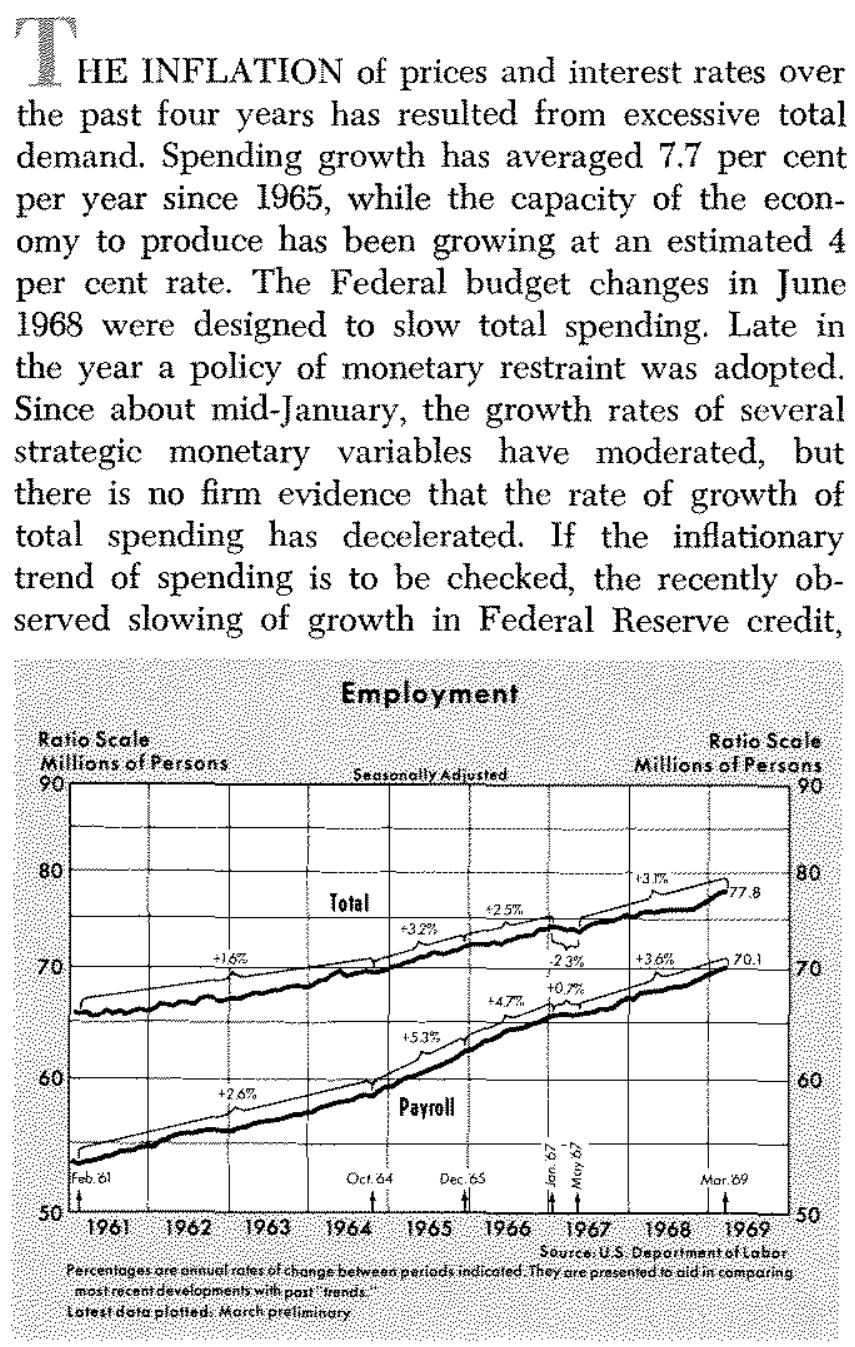

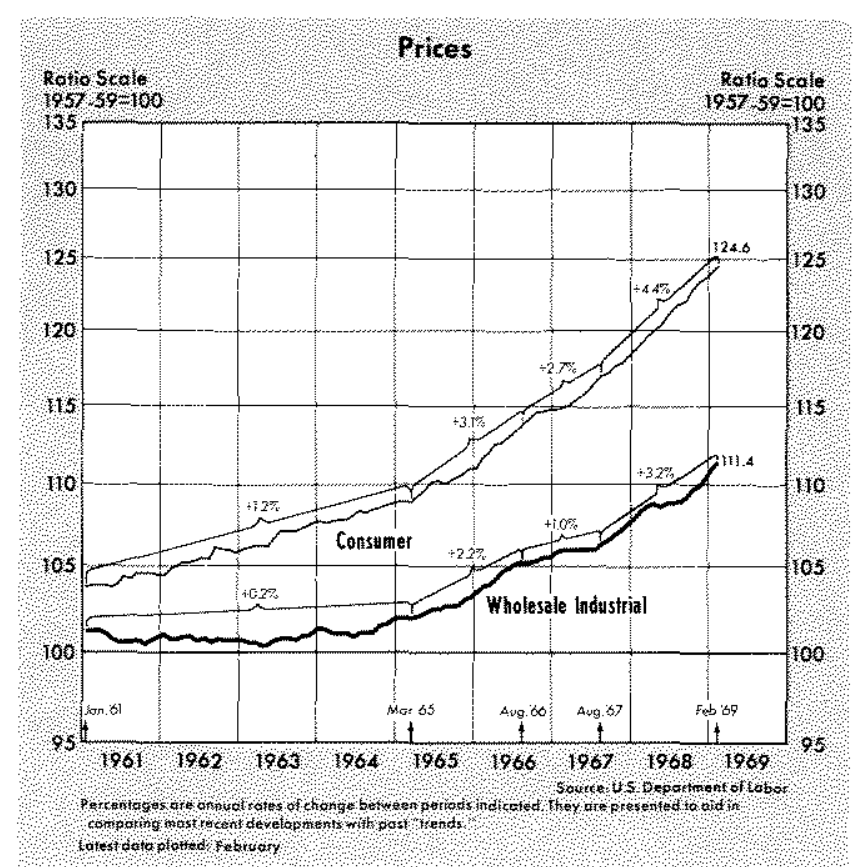

member bank reserves, monetary base and the money supply must be sustained.

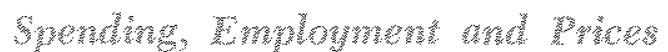

Total spending in the fourth quarter grew at an estimated 8 percent annual rate, about the same as the average rate for the past four inflationary years. Spending growth in the last half of 1968 was at an 8.3 per cent annual rate, compared with a 10.6 per cent rate in the first half. Though slight moderation

Page 2 


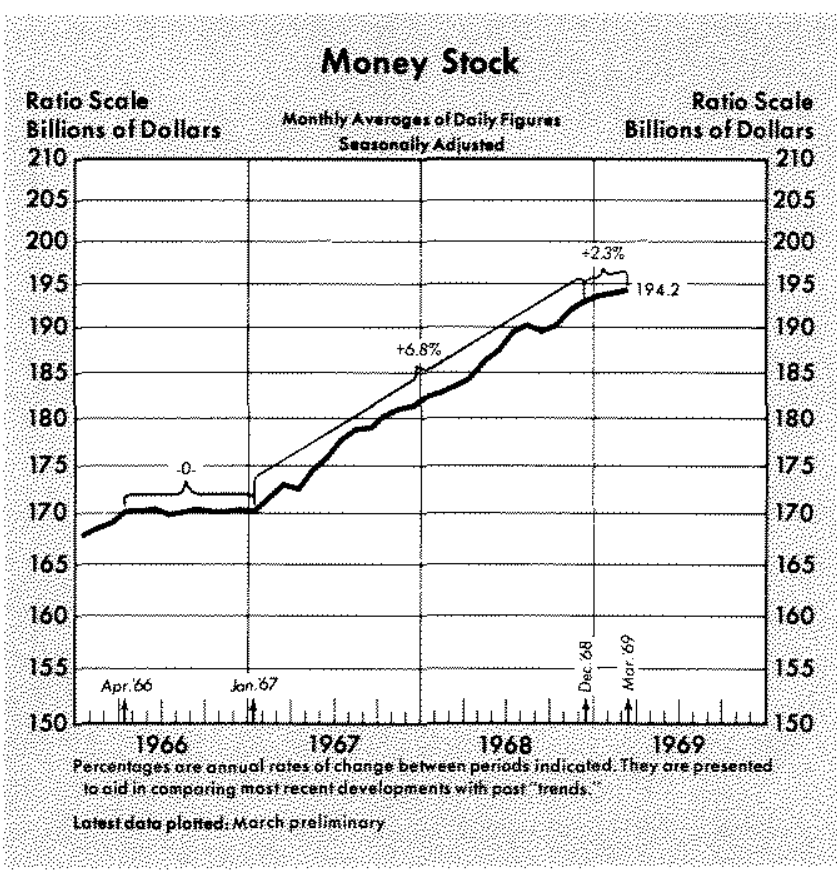

from early 1968 may be evident, total spending continued to advance well in excess of the growth rate of the economy's productive potential.

Developments since late 1968 show no indication of a significant decline in the rate of increase of total spending. Industrial production has risen at a 6.5 per cent annual rate since September compared with a 5 per cent rise in the previous year. Payroll employment has increased at a 6 per cent rate since fall compared with 2 per cent in the previous year. Wholesale prices of industrial commodities have risen at about a 4.5 per cent amnual rate since August, compared with a 2.5 per cent rate in the previous year.

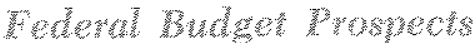

The influence of the June 1968 fiscal action on total spending and inflation appears to have been slight. The restraining effects of the tax surcharge and the slowdown in Federal spending growth in the last half of 1968 were offset by stimulative monetary actions and private anticipations of continued inflation, both of which provided impetus to private spending.

Recently announced revisions of budget expenditure plans indicate a more restrictive course for fiscal actions than was first planned in January. The highemployment budget is expected to rise from a $\$ 4$ billion annual rate of surplus in the first quarter to $\$ 8$ billion in the second quarter, then revert to about a $\$ 6$ billion rate of surplus by late 1969. Adjusted for make-up tax payments in the second quarter, the Federal budget is now planned to show more rapid growth of receipts than of expenditures during 1969. Revised fiscal plans may be viewed as providing slightly more restraint on total spending as 1969 progresses.

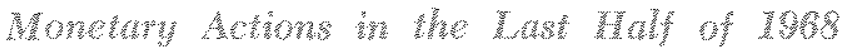

Judgment differs greatly as to the influence of monetary factors on the course of total spending in the last half of 1968 and in early 1969, depending on which monetary measures are considered and how they are interpreted. As enactment of the fiscal prow gram became assured in late May of 1968, the financial and business public was persuaded that the Government's demand for funds would be reduced. Private demand for loan funds declined and, consequently, interest rates declined. Lower market interest rates relative to Regulation $Q$ ceilings (maximum rates which commercial banks are permitted to pay on time deposits) resulted in a large flow of funds to banks. The reduction of discount rates in August was a minor adjustment to lower market interest rates. By September and October, the demand for loan funds was again pushing market interest rates upward.

The rapid growth of bank credit and money plus time deposits $\left(\mathrm{M}_{2}\right)$ in the last half of 1968 was caused by the reduced level of market interest rates relative to Regulation $Q$ ceilings. To the extent that there was a decline in the rate of growth of demand

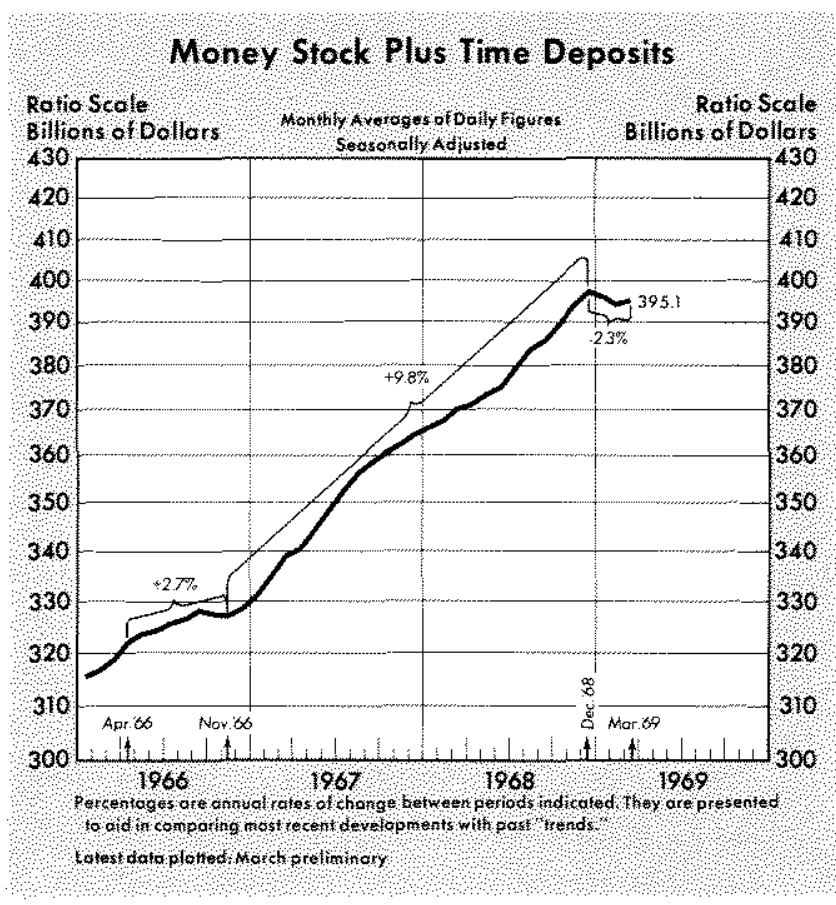


deposits and money stock $\left(\mathrm{M}_{1}\right)$ after midyear, it appears to have been fostered by absorption of reserves by the increased time deposits rather than by any tightening of policy.

Monetary aggregates more closely related to central bank actions, when viewed collectively, did not advance much differently in the last half of the year than in the first half. Federal Reserve credit grew less rapidly in the second half, and member bank reserves more rapidly. The monetary base grew at a rather steady 6.5 per cent annual rate throughout the year. Growth of the money stock was at a 6.8 per cent annual rate in the first half of the year and at a 6.2 per cent rate in the last half.

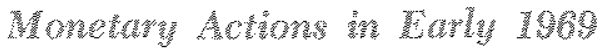

There are clear indications that monetary infuence has become restrictive since late 1968. The monetary base has increased at a 3.4 per cent annual rate in the past three months, well below the 6.5 per cent rate of the past two years. Money stock growth has slowed to a 2.3 per cent rate in the last three months, after increasing 6.5 per cent in the previous year. The money stock defined to include U.S. Government deposits has declined at a 1.2 per cent annual rate in the past three months, compared with a 6.2 per cent increase in the previous 12 months.

If the deceleration in growth of money and other strategic monetary aggregates is sustained, given the apparent continued strength in loan demand, interest rates may well continue to rise, but such increases are likely to be temporary. When the rate of growth of total spending and inflationary expectations decline, the demand for loan funds will be slowed, and interest rates may be expected to decline.

Market interest rates have risen well above the rates which banks are allowed to pay on deposits, resulting in a channeling of funds outside banks since December, reversing the process of the last half of 1968 . Reflecting these developments, the outstanding amounts of bank credit and $\mathrm{M}_{2}$ have declined. Such declines do not necessarily indicate severe monetary restraint. When banks are restricted by Regulation $Q$ from paying competitive rates on earning assets, the demand for time deposits declines. As the quantity of $\mathrm{M}_{2}$ has been limited by Regulation $Q$, the demand has declined as well. When the flow of funds through banks is restrained by Regulation Q, the flow through other channels is increased correspondingly.

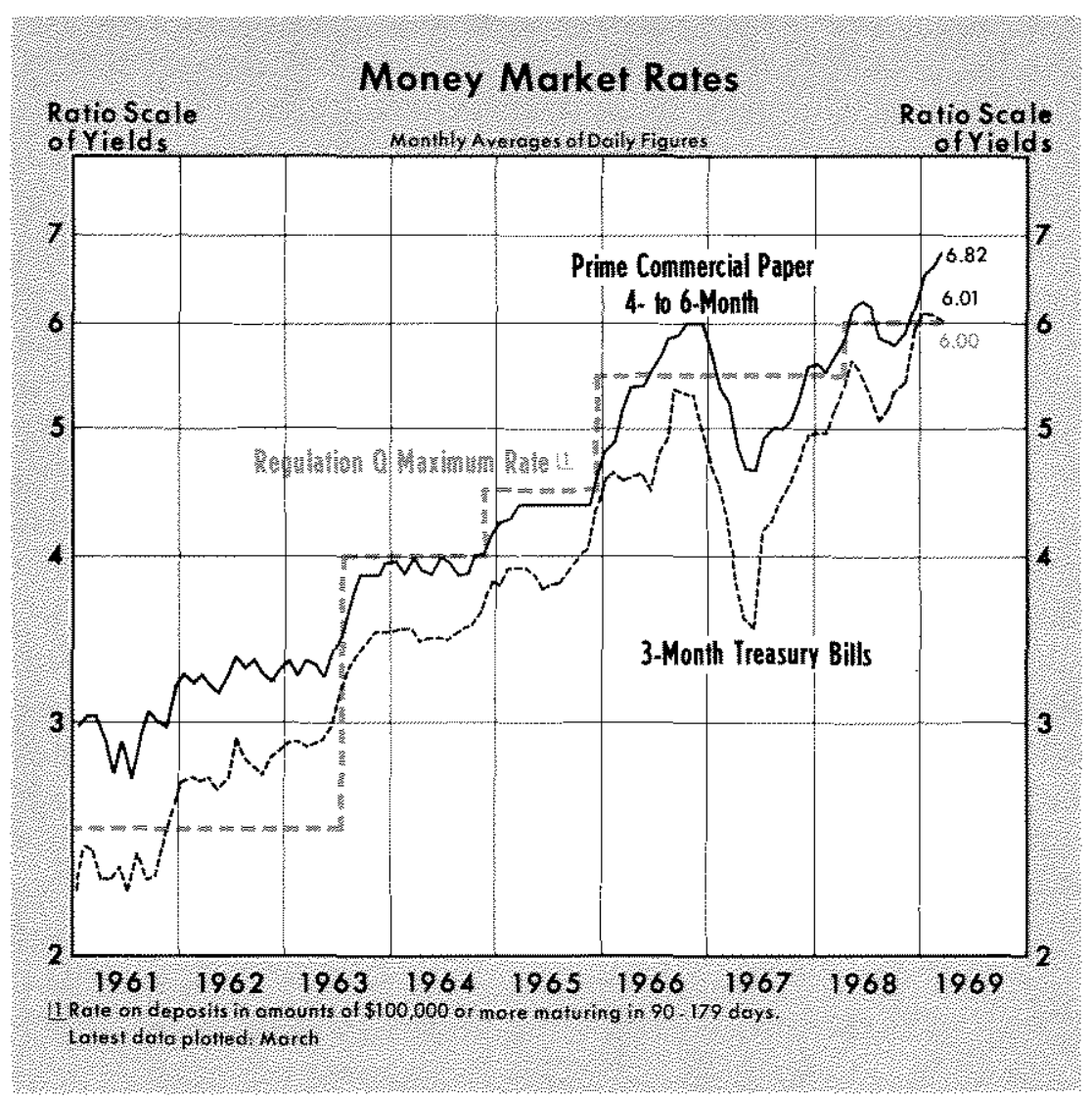

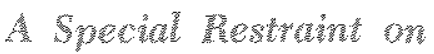

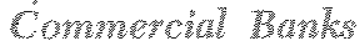

Credit markets in general have been placed under special pressure due to the great demand for loan funds, and since mid-January, by a slowing in the growth of Federal Reserve credit, monetary base, bank reserves, and money $\left(\mathrm{M}_{1}\right)$. Commercial banks have. been in particular difficulty because they are subject to the exceptional restriction of Regulation $Q$ on the flow of funds, and more recently to a higher reserve requirement on demand deposits.

The effect of Regulation $Q$ ceilings is to reroute the flow of funds away from commercial banks when narket interest rates rise above such ceilings, without clearly limiting the marginal creation of money and credit. If Regulation $Q$ ceilings had been raised in November, and banks had been able to retain and gain deposits, there probably would have been no less over-all monetary restraint, but unnecessary 


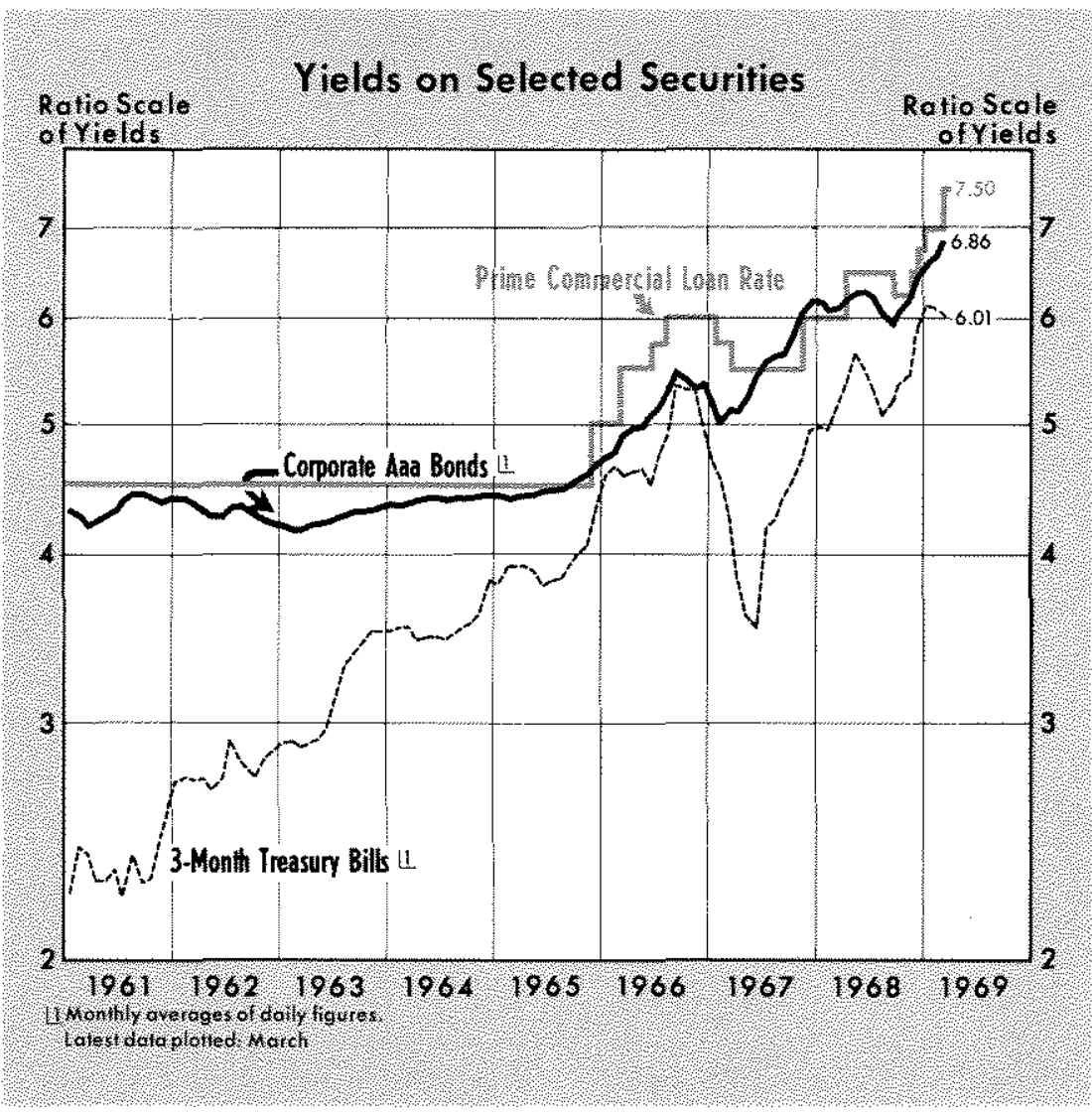

\section{Ban Woan Rates}

Rates charged by commercial banks have been under strong upward pressure because of buoyant total spending in the economy. This pressure has been especially intense because the limitation on interest rates which banks can pay on deposits has severely limited the supply of funds to banks. Banks have been under pressure to increase their rates even faster than interest rates have been rising generally. One way to relieve upward pressure on bank loan rates would be to reduce limitations on the supply of funds to banks by raising Regulation Q ceilings. However, such an action would have little effect on the basic supply and demand forces operating on interest rates.

Interest rates, in general, can be reduced only by slowing the growth in total spending and thereby the total demand for loan funds. Containment of total spending and inflation is contingent on continuation of reduced rates

wrenchings of the financial system as funds were rerouted would have been avoided.

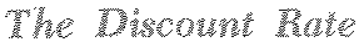

As market interest rates have risen since last September in response to increasing demand for loans, they have also risen relative to the Federal Reserve discount rate. In September the commercial paper rate was 57 basis points above the discount rate, and in March the spread increased to 98 points. Bank borrowings from Reserve Banks increased from $\$ 515$ million last September to $\$ 750$ million in March, and to over $\$ 1$ billion just prior to the raising of the discount rate from $5^{3 / 2}$ per cent to 6 per cent on April 4.

These borrowings were stimulated by the increasingly advantageous spread between discount rates and market rates, by the demand for loan funds, by the deprivation of funds to the banks by limits on interest rates they can pay, and after mid-January, by slower growth in strategic monetary aggregates. The increased borrowing from the Federal Reserve, in and of itself, has been conducive to the increase of bank reserves and thereby to expansion of bank credit, demand deposits and the money supply. of growth of Federal Reserve credit, the monetary base, bank reserves, and the money supply.

\section{Summats}

Commercial banks have been placed under special pressure by the workings of Regulation $\mathrm{Q}$, though this does not indicate pressure from the monetary authority on credit markets in general. Monetary restraint comes only from reduced monetary expansion. There are substantial indications that such a slowing has occurred, but the impact of these slower growth rates will be effective only if they are sustained over a longer period of time.

Experience of the past 20 years indicates that the effects of monetary action on total spending are not felt for several months, and that price effects of total spending are not observed until several quarters after that. If the recently reduced rate of monetary expansion is continued, growth of total spending is likely to moderate significantly by midyear. However, even when firm indications of deceleration of total spending become evident, significant deceleration of price increases may not become apparent for several quarters. 